\title{
As neuroses traumáticas e o modelo da dor física em "Além do princípio do prazer": relações entre trauma e narcisismo no segundo dualismo pulsional freudiano
}

\author{
Traumatic neurosis and the physical pain model in "Beyond the Pleasure
} Principle": relations between trauma and narcissism in the second Freudian drive dualism

\section{Josiane Cristina Bocchi*}

\begin{abstract}
Resumo: Este artigo discute as implicações do segundo dualismo pulsional freudiano para a economia narcísica e o conceito de trauma, fenômenos que despontam no corpo teórico da segunda tópica psíquica. Discute-se o modelo econômico da dor física e sua retomada em Além do princípio do prazer, como um marco renovado para a teoria do trauma e sua relação com a fixação em formas de sofrimento psíquico e de adoecimento. Conclui-se que um desenvolvimento teórico sobre a dor e sua relação com o masoquismo erógeno e moral são contribuições para elucidar o retorno de formações narcísicas sobre o Eu.

Palavras-chave: Dor física; Trauma; Narcisismo; Masoquismo; Corpo; Ego
\end{abstract}

\begin{abstract}
This paper discusses the implications of the second Freudian pulsational dualism to the narcissistic economy and the concept of trauma, phenomena that arise in the theoretical body of the second psychic topic. The economic model of physical pain and its return in Beyond the Pleasure Principle are discussed, as a renovated mark for the theory of trauma and its relation with the fixation in forms of psychic suffering and illness. It is concluded that a theoretical development about pain and its relation with erogenous and moral masochism are contributions to elucidate the return of narcissistic formations about the Self.
\end{abstract}

Keywords: Physical pain; Trauma; Narcissism; Masochism; Body; Ego

\section{O problema da dor entre a primeira para a segunda tópica psíquica}

O presente trabalho tem como objetivo destacar e desenvolver as implicações do novo dualismo pulsional - pulsões de vida e pulsões de morte - para a economia narcísica e o traumático que desponta nesse novo corpo teórico. Embora Freud não tenha desenvolvido o problema do narcisismo face às pulsões de morte, o conceito é usado como subsídio teórico para explicar a ligação [Bindung] do excesso traumático e outros

*Professora de Psicologia, Universidade Estadual Paulista Júlio de Mesquita Filho, Bauru, SP. E-mail: josiane.bocchi@unesp.br ORCID: https://orcid.org/0000-0002-2657-9490 
fenômenos da compulsão à repetição, alguns dos quais alteram a tessitura do Eu e sua relação objetal, como será discutido na segunda parte do trabalho.

Primeiro, serão discutidas algumas inovações do célebre texto freudiano de 1920 a respeito da dor física, do trauma e da relação do aparelho psíquico com os perigos externos. É curioso que um dos traços fundamentais das neuroses traumáticas - e pouco abordado na literatura psicanalítica - seja o papel da lesão física no trauma concorrer para o impedimento da neurose. A lesão orgânica teria algum efeito de proteção contra a neurose? Afinal, Freud afirma, mais de uma vez, que doenças orgânicas teriam um efeito de remissão sobre afecções narcísicas graves, como a melancolia e demência precoce e, além disso, episódios de dor e febre influenciam na libido corporal ${ }^{1}$. A dor física também foi referida por Freud como uma “pseudopulsão”, cuja meta é interromper a alteração do órgão e o desprazer².

Sendo assim, caberá também investigar, no presente artigo, como a dor física transforma-se em dor psíquica, o que se atribui, em 1920, a um efeito peculiar da economia narcísica entre eu, corpo e libido e, posteriormente em Inibição, sintoma e angústia (1926), aos remanejamentos entre investimento narcísico (corporal) e investimento nos representantes de objeto.

No texto Além do princípio do prazer, publicado em 1920, Freud apresenta reformulações decisivas para a teoria pulsional ao introduzir as pulsões de morte e o princípio do Nirvana, assim como desenvolve conceitos de interesse teórico e clínico, como a reação terapêutica negativa e a noção de "captura" - a ligação [Bindung] - como resposta às intensidades liberadas no trauma. A partir do ensaio freudiano de 1920, a concepção de traumatismo terá que considerar o excesso de excitação como vinculado às vicissitudes das pulsões mortíferas e "pela dimensão pulsional não inscrita psiquicamente pelos processos de simbolização" 3 . Para Liana Bastos, a segunda teoria pulsional e a segunda tópica "reintroduzem o conceito de trauma, ligado ao desamparo" e oferecem uma releitura do ponto de vista econômico sobre a constituição do Eu e as perdas objetais ${ }^{4}$. Esta obra também reposiciona a compulsão à repetição em relação ao princípio de prazer e traz novas considerações metapsicológicas para a questão da dor e o seu papel no trauma.

O problema econômico da dor está em causa na concepção de traumatismo como efração e na distribuição da libido em 1920. A retomada do modelo da dor física reascende uma ideia cara ao pensamento freudiano, qual seja, a estimulação advinda de um abalo externo (choque mecânico, acidentes, eventos traumáticos reais) se transforma em uma excitação interna, e passa a atuar peremptoriamente desde o interior do aparelho psíquico

\footnotetext{
${ }^{1}$ FREUD, Além do princípio do prazer, 157. Em Introdução ao narcisismo, Freud tratou a questão de forma mais ampla, envolvendo também a hipocondria e a erogeneidade.

${ }^{2}$ FREUD, O recalque, 1915.

${ }^{3}$ KUPERMANN, Estilos do cuidado: a psicanálise e o traumático, 50.

${ }^{4}$ BASTOS, Eu-corpando: o ego e o corpo em Freud, 135.
} 
como pulsão. Tal perspectiva coloca em evidência uma suspensão da distinção entre os registros do interno e externo do aparelho psíquico, contrariando impasses dicotômicos da modernidade ${ }^{5}$. Esta acepção da pulsão como choque entre cargas de excitação exterior e interior, embora já estivesse presente na escrita freudiana, em formulações teóricas de 25 anos atrás, será retomada e amplamente desenvolvida em Além do princípio do prazer, graças ao acréscimo das pulsões de morte na nova economia pulsional.

Além disso, Freud é incisivo a respeito da noção de ruptura/efração no trauma, de modo análogo aos efeitos provocados pela dor física no psiquismo:

Acredito que não podemos compreender o conceito de trauma sem vinculálo a uma ruptura na camada protetora contra estímulos, a qual sabemos sob circunstâncias normais operar de modo eficaz. Não há dúvida de que um acontecimento como o trauma exterior provoca uma grave perturbação na economia energética do organismo ${ }^{6}$.

Ele acrescenta na sequência que o desprazer específico da dor física seria "consequência do rompimento do escudo protetor em uma área limitada. As excitações provenientes dessa região periférica afluiriam então continuamente para o aparelho psíquico"7. É sabido que no Manuscrito $G$ da correspondência entre Freud e Fliess e no Projeto para uma psicologia científica $(1950 / 2003)^{8}$, Freud já abordara a dor e a anestesia sob o ângulo do traumatismo como violação. Todavia, em Além do princípio do prazer, a dor emerge como um modo de defesa narcísica que opera com a bindung, num trabalho que visa retomar o domínio do princípio de prazer.

O elemento novo nas formulações sobre o problema da dor no momento da virada dos anos 20 é reconhecer uma função de ligação na mobilização energética do aparelho psíquico no tempo pós-traumático e a generalização dessa concepção de trauma para outras afecções clínicas. Até aquele momento não era evidente que algumas modalidades de sofrimento vinculadas ao trauma não se encontravam apenas nas neuroses traumáticas. Freud afirma que a tarefa do aparelho será ligar as energias livres que fluem sob a forma do processo primário. As falhas nesse processo geram perturbações análogas às neuroses traumáticas. Provavelmente, a referência aqui se enderece aos casos de hipocondria e de melancolia, Freud compara a neurose traumática a estas duas afecções em função da presença de sofrimento subjetivo muito intenso e de um conflito do eu. Tais relações ficarão mais claras em outro texto de Freud, Inibições, sintomas e angústia (1926), principalmente por considerarem a problemática que envolve o luto e da perda do objeto.

\footnotetext{
${ }^{5}$ BOCCHI; PEREZ; BOCCA, Ontologie sans miroirs, 2019.

${ }^{6}$ FREUD, Além do princípio do prazer, 153-54.

${ }^{7}$ FREUD, Além do princípio do prazer, 154.

${ }^{8}$ O texto foi escrito em 1895, porém publicado em 1950. A versão consultada é de 2003, tradução de Osmyr Faria Gabbi Jr. Para efeito de maior clareza, usaremos apenas Projeto (1895).
} 
Não é novidade que Freud não apresentou um estudo sistemático sobre a dor. Pelo contrário, quando aborda o fenômeno o faz brevemente, embora de forma densa, como em seções específicas do Projeto (1895), no O recalque (1915), na seção IV de Além do princípio do prazer e no adendo C de Inibição sintoma e angústia e outras passagens que Freud mesmo reconhece como sendo indicações e reflexões. A dor está longe de ser um tema amplamente abordado na literatura psicanalítica pós-Freud e até os dias atuais, embora seja assinalada como contendo elementos de uma teoria original no pensamento freudiano, como em J.-B. Pontalis ${ }^{9}$ e A. Aubert ${ }^{10}$. Haveria uma certa reticência em admitir e desenvolver o trabalho com a noção da dor física no campo psicanalítico, como indicam Nasio $^{11}$ e novamente Pontalis ${ }^{12}$. A psicanálise deu pouca atenção para o afeto da dor ao longo de sua história. Aborda-se os problemas do luto e da perda, à exemplo de André Green, mas há pouco sobre a dor, sua gênese, suas modalidades e seus desdobramentos.

Contudo, a dor está presente nos escritos de Freud como uma experiência inquietante e persistente, a partir da qual este trabalho procurará demonstrar o aspecto paradigmático da dor para a discussão do trauma, para a fixação em formas de sofrimento que tenham relação com a reação terapêutica negativa e o masoquismo primário, elementos conceituais ligados à teorização da pulsão de morte, também desenvolvidos em outros trabalhos de Freud do início da década de 20, como será abordado.

\section{Modelo da vivência de dor: 25 anos antes}

Será necessário retomar os postulados da dor e da vivência de dor, desenvolvidos no Projeto (1895), onde se apresenta, pela primeira vez, os efeitos da dor física sobre o funcionamento psíquico. A dor física - sempre de origem externa - irrompe as barreiras de proteção anti-estímulo e atuará como um estímulo interno contínuo, donde se tornará duradoura em relação a outros processos psíquicos. Freud descreve a dor como um indicativo de falha no dispositivo psíquico, uma condição anormal, mas não patológica, devido à ruptura e transbordamento dos mecanismos perceptivos (as terminações sensoriais nervosas) destinados a proteger o sistema mnemônico contra a recepção de grandes quantidades de estímulos provenientes do mundo externo. Destaca-se que nessa definição de Freud a dor já aparece como uma experiência limite e disruptiva entre o psíquico e o mundo externo.

Tal efração é tão intensa para o aparelho, de modo que "a dor coloca tanto o sistema $\varnothing$ como o $\Psi$ em movimento, não havendo para ela nenhum impedimento de condução; ela é o mais imperioso de todos os processos. Dessa maneira os neurônios $\psi$ parecem ser

\footnotetext{
${ }^{9}$ PONTALIS, Entre o sonho e a dor, 2005.

${ }^{10}$ AUBERT, A originalidade de uma teoria freudiana, 2017.

${ }^{11}$ NASIO, A dor física: uma teoria psicanalítica da dor corporal, 2008.

${ }^{12}$ PONTALIS, Entre o sonho e a dor, 2005.
} 
permeáveis para ela"13. Os neurônios $\varnothing$ correspondem à percepção, enquanto os $\psi$ são responsáveis pela memória.

No Projeto, também são introduzidos dois tipos de vivências primordiais para a constituição do psiquismo: a "vivência de satisfação" e a "vivência de dor". Esta última se inicia com uma experiência dolorosa qualquer, em que afluem de grandes quantidades de excitação externa para o sistema de memória, sendo descrita por Freud em termos de suas consequências para o psiquismo:

A dor produz em $\Psi: 1$. Um grande aumento de nível, sentido como desprazer por $\omega$ 2. Uma inclinação para a eliminação, que pode ser modificada de acordo com certas direções; 3. Uma facilitação entre esta e uma imagem recordativa do objeto que excitou a dor. Além disso, não resta dúvida que a dor tem uma qualidade especial que se faz sentir ao lado do desprazer ${ }^{14}$.

Notem que a dor não é o desprazer, mas se faz sentir como similar ao desprazer, além de suscitá-lo pelo aumento do nível de excitação, associado agora a um movimento de eliminação - uma "inclinação" à descarga -, por sua vez, fortemente associada a representação de um objeto hostil, este que teria sido a causa de tal vivência.

A vivência de dor consiste propriamente na reprodução desse circuito associativo, quando uma percepção ocupar novamente a imagem recordativa do objeto hostil, mas agora com uma diferença: "produz-se um estado que não é doloroso, mas que, todavia, é similar a ele [...]. Na própria vivencia dolorosa era a $\mathrm{Q}$ irruptiva de fora que aumentava o nível $\Psi$. Nesta reprodução - no afeto -, só coube penetrar a Q que ocupa a recordação"15.

Como a ocupação se dá na imagem do objeto, e não em todo o sistema $\Psi$, Freud deduz que o desprazer seja liberado do interior do corpo e introduz a hipótese dos neurônios "secretores" ou "neurônios chave", que não eliminam quantidades internas, mas as fornecem indiretamente. Não se trata de discorrer sobre estes neurônios, o que interessa é que a associação (“facilitação”, na terminologia do texto) entre eles e a imagem é suficientemente forte, "de modo que o desprazer é liberado agora no afeto"16. Essa liberação tem uma origem corporal e, veremos, pulsional, e também estaria presente na liberação sexual, sublinha Freud. A liberação do afeto é imediata, enquanto nos estados de desejo da vivência de satisfação é por somação: "Da vivencia dolorosa resulta uma repulsa, uma aversão, a manter ocupada a imagem recordativa hostil" ${ }^{17}$ e deixando uma compulsão para sua eliminação, que Freud chama de “defesa primária” ou repressão. Freud reconhece

\footnotetext{
${ }^{13}$ FREUD, O projeto, 186.

${ }^{14}$ FREUD, O projeto, 198.

${ }^{15}$ Ibidem.

${ }^{16}$ Ibidem.

${ }^{17}$ FREUD, O projeto, 199.
} 
a dificuldade de demonstrar como a imagem do objeto tem que ser que ser rapidamente desinvestida, se não o indivíduo estaria exposto à alucinação do perigo a cada vez que a vivência dolorosa fosse rememorada. Ele fará isso recorrendo a uma hipótese adaptativa ligada à psicogênese do Eu e ao trabalho que essa instância terá no domínio das excitações excedentes.

Em função do paralelo que faremos entre as teorizações do Projeto (1895) e as noções que ganharão terreno em Além do princípio do prazer, é preciso assinalar que o registro da vivência de dor ativa um modo primitivo de defesa psíquica que, por sua vez, influirá nos demais mecanismos defensivos do funcionamento psíquico normal e patológico. Pode-se dizer que a dor estaria ligada a um modelo de efração e, ao mesmo tempo, de reação endopsíquica. O desprazer da rememoração dolorosa resulta da liberação de quantidade própria ao aparelho, e não mais de fora, do mundo externo. Freud designa esse desprazer específico como "afeto". Assim, as primeiras rememorações de uma vivência de dor dão origem ao afeto e à defesa primária intensa.

Como já dito, essa resposta reflexa seria prejudicial nos casos em que se tenha apenas uma lembrança insignificante do objeto hostil, e não a experiência de uma situação dolorosa na realidade. Sendo necessário, do ponto de vista adaptativo do aparelho psíquico, que houvesse uma inibição da defesa primária.

$\mathrm{Na}$ terceira parte do Projeto, Freud formula a hipótese de que a inibição da ocupação intensa do objeto hostil só seria possível depois de consumado um trabalho repetitivo de ligação da excitação excedente. Assim, as primeiras recordações do objeto hostil, a liberação do afeto e a inclinação para a defesa primária não seriam evitadas até que surgisse uma organização como o eu, capaz de interferir no curso ideo-afetivo da repetição da vivência da dor, buscando um domínio sobre a excitação. Domínio esse que seria conquistado justamente a partir da inibição das vias afetivas anteriormente facilitadas, através das "ocupações laterais" do eu e do mecanismo da atenção.

O que acontece com as recordações capazes de afeto até que elas sejam domadas? Não cabe ver aí que o "tempo", a repetição, enfraqueça sua capacidade de afeto, pois esse momento normalmente contribui para reforçar uma associação. Sem dúvida algo tem de passar-se no "tempo" nas repetições encarregadas dessa sujeição, e isso não pode ser senão uma referência ao eu e ou ao poder que suas ocupações obtenham sobre a recordação ${ }^{18}$.

Uma vez adquirido o domínio de certos complexos representativos por parte do eu, a ocupação da representação do objeto hostil se limitaria a um mínimo que apenas sinaliza ao curso associativo que a inclinação à descarga conduz ao desprazer e deve ser evitada. A ação do Eu, impulsionada primeiramente pela defesa primária, passará a inibir a ocupação

${ }^{18}$ FREUD, O Projeto, 253. 
massiva da imagem do objeto, forjando ocupações laterais, de modo que o caminho de eliminação do afeto antes fortemente facilitado seja, agora, percorrido apenas por uma fração da quantidade, gerando uma rememoração e não uma alucinação do objeto hostil.

Nesse sentido, a vivência dolorosa teria como efeito imediato um processo rememorativo repetitivo acompanhado pela produção de afeto, que embora seja penoso, não é o mesmo que o desprazer. Freud insistiu nessa distinção em 1895 e em 1920, quando ele volta a falar da especificidade do desprazer na dor. Ora, o que está em jogo é mais complexo, um sofrimento ou uma afecção incitada a partir do interior do aparelho psíquico (afeto desprazeroso) emergiria como consequência de um agravo anterior incitado pelo mundo externo. Uma dor psíquica emergiria como efeito de uma dor física. Como dissemos no início da apresentação da vivência de dor, a dor irrompe nas barreiras sensoriais (os "dispositivos de proteção") e passa a agir como como uma estimulação interna que, sob certas circunstâncias, tornar-se-á contínua. Pontalis ${ }^{19}$ chama a atenção para alguns aspectos fundamentais da definição da dor no Projeto (1895). Primeiro, essa definição não vai mudar: a dor decorre de uma violação do para-excitação, "ela produz uma descarga interna, que poderíamos chamar de efeito de implosão "’o, pela excitação pulsional constante. Assim, ela emana de uma dupla periferia, seja via percepção, mundo externo (a pele, o órgão atingido), seja também pela via do interior de um 'eu-corpo',

Como se, com a dor, o corpo se transformasse em psique e a psique em corpo. Para esse eu-corpo, ou para esse 'corpo psíquico', a relação continente conteúdo prevalece, quer se trate de dor física ou psíquica ${ }^{21}$.

Não há como negar o valor heurístico dessa asserção quando levada para pensar o registro do trauma e suas fixações. Ao mesmo tempo, parece haver para Freud uma função prototípica e estrutural no fenômeno da dor - Pontalis vem elucidar isso ao sublinhar esse efeito de "acoplamento do fora e do dentro"22. Dor não é apenas mais um afeto desprazeroso ou um sintoma primário, mas o problema da dor coloca em jogo as linhas de ruptura, reversão ou tangência entre contornos do psiquismo e corpo.

A respeito da emersão de um eu-corpo a partir dos primeiros registros dolorosos, uma vez que o Eu iniba a representação hostil e o afeto associado a ela, também "possibilita um critério de diferenciação entre percepção e recordação" 23 , e assim os processos de pensamento passam a ser desviados das representações hostis ou ameaçadoras, ou seja, estas seriam excluídas das associações conscientes. É provável que as representações associadas a dores físicas estabeleçam ao menos parte daquilo que não

\footnotetext{
${ }^{19}$ PONTALIS, Entre o sonho e a dor, 2005.

${ }^{20}$ PONTALIS, Entre o sonho e a dor, 268.

${ }^{21}$ PONTALIS, Entre o sonho e a dor, 271.

${ }^{22}$ PONTALIS, Entre o sonho e a dor, 278.

${ }^{23}$ FREUD, O projeto, 203.
} 
deve ser lembrado. Podemos inferir que a dor excluiria do acesso à consciência uma série associativa vinculada às representações hostis originárias.

Isto nos faz levantar a questão de que a dor estaria relacionada, então, a uma forma de repressão, esquecimento ou suspensão do sofrimento psíquico ligado a representações que gerem angústia. Voltaremos a esse ponto quando discutirmos a relação entre dor e angústia na ausência do objeto externo.

\section{Neuroses traumáticas e narcisismo}

A questão do impacto da dor sobre o psiquismo volta a ser alvo da atenção de Freud em Além do princípio do prazer, quando é abordada a relação do aparelho psíquico com os perigos da realidade e o traumatismo decorrente. Freud demonstra o papel da lesão física e da dor corporal, valendo-se das descobertas da década de 10 - sobretudo teoria do narcisismo e do masoquismo -, revelando a correspondência entre a experiência da dor e um embotamento da capacidade de pensar, mas também um modo de regulação narcísica entre eu, supereu e sofrimento neurótico de ordem corporal e psíquica.

A dor reaparece no cenário psicanalítico nos mesmos termos que em 1895, referente ao papel do escudo protetor sensorial e da transformação de uma perturbação externa em uma mobilização interna: “É provável que o desprazer específico da dor física seja consequência do rompimento do escudo protetor em uma área limitada. As excitações provenientes dessa região periférica afluiriam então continuamente para o aparelho psíquico" ${ }^{24}$. Notem, novamente, o papel da periferia dos sistemas na produção da dor.

Uma das novidades que Freud traz sobre a dor no texto de 1920 é quanto às suas consequências para o psiquismo. Primeiro, ela demandará um alto custo de contrainvestimento do aparelho e terá como efeito um empobrecimento de outros sistemas psíquicos e suas funções (percepção, memória, juízo crítico, por exemplo), excluindo, mesmo que momentaneamente, a mediação do aparelho psíquico, devido ao efeito invasivo, imperativo e paralisante da dor, resultante do seu mecanismo reflexo.

Freud, em 1920, retoma o problema do trauma e da dor em conjunto e seguindo o que foi postulado 25 anos antes no modelo da vivência de dor como efração: violaçãoliberação do afeto; agora, na forma de contra-investimento, concentração do investimento narcísico. Por outro lado, a dinâmica dos investimentos narcísicos nos leva à segunda consequência importante para o psiquismo, a região corporal atingida no choque traumático terá um papel central na retração libidinal do eu e no domínio das excitações liberadas no trauma.

${ }^{24}$ FREUD, Além do princípio do prazer, 154. Grifos nossos. 
No caso da neurose traumática comum, destacam-se dois traços que poderiam ser tomados como ponto de partida parar uma reflexão que nos ajude a elucidar este enigma: primeiro, que o peso principal da causação parece recair sobre o fator surpresa, o susto, e segundo, que um ferimento ou ferida concomitante geralmente impede o aparecimento da neurose ${ }^{25}$.

Na sequência Freud distingue o susto [Schreck], o receio [Furcht] e o medo [Angst] na sua relação com o perigo externo e interno, a angústia. É interessante que o medo é referido a um estado de expectante, que cumpre uma função preparatória para o perigo, mesmo que este seja desconhecido, diz Freud. O receio envolve a presença de um objeto fóbico, portanto traz uma forma de objetivação da angústia. Então, seria o susto [Schreck] o responsável pelo fator surpresa, peça decisiva na montagem da situação traumática: "Não acredito que o medo [Angst possa provocar uma neurose traumática; no medo [Angst há algo que protege contra o susto [Schreck] e, portanto, também contra a neurose traumática” ${ }^{26}$. Esta concepção está na base da explicação do trauma como resultante da falta de prontidão para o medo - a falta de preparo libidinal e subjetivo - e não propriamente das intensidades do choque mecânico do acidente ou qualquer abalo que seja.

Freud aborda o segundo fator de proteção contra a neurose na seção IV, onde ele desenvolve uma hipótese econômica para explicar o papel da lesão corporal no trauma: "o fato de que a chance de contrair uma neurose é diminuída quando o trauma é acompanhado por um grave ferimento físico”27. A teoria do narcisismo é acionada aqui para dar conta desse fenômeno, através de duas observações anteriores de Freud, uma em Três ensaios de teoria sexual (1905) e a outra em Introdução ao narcisismo (1914): o abalo físico é uma das fontes de excitação sexual. O choque libera um quantum de energia sexual. Esse fator participa também da explicação do por que uma dor externa equivale a uma excitação interna, atuando de modo análogo à pulsão. A outra observação, feita em 1914, a respeito da relação entre narcisismo, vida amora e doença orgânica, é que o doente recolhe sua libido, o que influencia na economia libidinal das neuroses narcísicas. Freud assinala que tal fato ainda não foi suficientemente valorizado nem mesmo na teoria da libido:

perturbações graves na distribuição da libido, como ocorrem, por exemplo, nos casos de melancolia, cessam temporariamente quando aparece uma enfermidade orgânica intercorrente. $\mathrm{O}$ mesmo também acontece até numa

\footnotetext{
${ }^{25}$ FREUD, Além do princípio do prazer, 139. Grifos nossos.

${ }^{26}$ FREUD, Além do princípio do prazer, 140.

${ }^{27}$ FREUD, Além do princípio do prazer, 157.
} 
Dementia praecox já desenvolvida, a qual, quando sobrevém uma doença orgânica, pode sofrer em algum grau uma reversão passageira ${ }^{28}$.

No adoecimento, é comum o enfermo ficar indiferente a tudo, havendo um recolhimento dos investimentos libidinais para o eu, para reenviá-los posteriormente, quando curado: “... enquanto sofre, também retira de seus objetos de amor o interesse libidinal, deixa de amar" ${ }^{29}$. Na hipocondria, a dor e sensações corporais também sugerem um recolhimento da libido. A diferença entre enfermidade e hipocondria reside na presença ou não do órgão lesado. Mas Freud fala em alterações de órgão também na hipocondria, porém "de outra ordem", ou seja, o corpo também é estimulado na hipocondria, mas a partir dele mesmo, devido herança das zonas erógenas e sua propriedade erógena. É a capacidade do corpo de ser estimulado por estímulos externos e internos (noção de "erogeneidade" e também ego corporal) e sua relação com o retorno das formações narcísicas para o eu auxiliam na compreensão da hipocondria. Freud (1914) diz que a estimulação de determinada parte do corpo exerce nele um efeito semelhante ao da distribuição da libido nas enfermidades orgânicas (ou dor física): tanto a dor oriunda de uma formação psíquica (os casos de hipocondria e melancolia, por exemplo), como a dor física (as enfermidades), ambas teriam no corpo uma distribuição libidinal parecida.

Ora, a economia libidinal do narcisismo é interessante, quando Freud (1920) diz que o trauma psíquico nas neuroses de guerra é menor quando acompanhadas de ferimentos físicos, o superinvestimento narcísico do órgão atingido é importante na ligação do excesso de excitação liberado no choque do trauma. Voltando à seção IV de Além do princípio do prazer(1920), em síntese, encontramos:

Assim, a força [Gewalt liberaria o quantum de excitação sexual que em razão da falta de preparação para o medo [Angstvorbereitung], produziria um efeito traumático. Um efeito físico que ocorre simultaneamente teria a capacidade de mobilizar uma camada de sobreinvestimento narcísico sobre o órgão em sofrimento, utilizando a energia desse sobreinvestimento para capturar [binden] o excesso de excitação ${ }^{30}$.

Com efeito, em 1920, Freud já dispunha das formulações sobre os fenômenos narcísicos da hipocondria, da melancolia e da enfermidade orgânica, indicando uma via investigativa a partir da qual os processos subjetivos normais e patológicos envolvidos na produção da dor revelam-se mais complexos do que o fenômeno da somatização. Este fenômeno, algumas vezes, é pensado como sintoma ou mecanismo patogênico equiparável a um déficit de mentalização ou perda da capacidade de simbolização, como em trabalhos

\footnotetext{
${ }^{28}$ FREUD, Além do princípio do prazer, 157.

${ }^{29}$ FREUD, Introdução ao narcisismo, 79.

${ }^{30}$ FREUD, Além do princípio do prazer, 157.
} 
de Pierre Marty ${ }^{31}$ e Joyce McDougall ${ }^{32}$, por exemplo. Vale dizer que a noção de somatização apresenta algumas confusões e carece de maiores desenvolvimentos, mesmo no campo da psicossomática $^{33}$. O texto Além do princípio do prazer traz contribuições conceituais que permitem ampliar a perspectiva da dor, pois o problema é exposto em termos metapsicológicos e retoma as primeiras reflexões do autor, agora podendo anexar uma conceitualização sobre o trauma psíquico e os efeitos do narcisismo estrutural. São delineados os aspectos tópicos e econômicos da dor e da lesão orgânica no trauma, revelando um papel inusitado e regulador entre o somático e o psíquico.

Ocorre que "De todos os lados é convocada a energia de investimento para que a área afetada receba uma carga de energia com uma intensidade equivalente à da invasão" ${ }^{34}$. Fica estabelecida também uma relação inversa entre estoque de investimento em estado de repouso e capacidade de receber afluxos externos de excitação e capturar tais excessos, “atá-los” [binden] psiquicamente. Essa colocação de Freud pede algumas considerações, que faremos na etapa final deste trabalho.

Por ora, é possível inferir que a instalação de estados dolorosos gera um excesso no psiquismo e acarreta como efeito um entorpecimento de processos psíquicos. Freud dirá um empobrecimento de outros sistemas psíquicos, como a atenção, a percepção e o pensamento. Uma vez que esses sistemas sejam novamente reinvestidos, a dor cessa; o que explica o fenômeno da suspensão do estado doloroso quando algo desvia a atenção de quem está com dor: "o fato marcante de que, quando há um desvio psíquico ocasionado por algum outro interesse, mesmo as dores físicas mais intensas deixam de existir” 35 .

O trauma físico libera uma excitabilidade de teor sexual e que, sem preparação para a angústia, favorece o traumatismo psíquico, mas a lesão física, quando presente, exige um contra-investimento narcísico sobre o órgão e produz ligação do excesso. É provável que seja esse mesmo motivo que faz com que doenças orgânicas tenham um efeito curativo sobre a melancolia e demência precoce.

A esse respeito, Annie Aubert discute o retorno narcísico da dor, que dispõe ao aparelho quantidades de energia para imobilizar a irrupção pulsional traumática. Tal ligação é de natureza dolorosa, mas também opera como um modo de defesa narcísico. Segundo ela, há uma teoria original sobre a dor no pensamento freudiano. A dor é a afecção e a defesa narcísica ao mesmo tempo: “a dor é um 'golpe duplo', ao mesmo tempo, efração e reação a essa efração" ${ }^{36}$. Esta autora amplifica o papel da dor no aparelho

\footnotetext{
${ }^{31}$ MARTY, Psicossomática do Adulto, 1993.

${ }^{32}$ MCDOUGALL, Teatros do corpo: o psicossoma em psicanálise, 2000.

${ }^{33}$ BOCCHI \& CAMPOS, As somatizações e o problema da dor no pensamento psicossomático clássico 2018,

${ }^{34}$ FREUD, Além do princípio do prazer, 154. Grifos nossos.

${ }^{35}$ FREUD, Inibição, sintoma e angústia, 160.

${ }^{36}$ AUBERT, A originalidade de uma teoria freudiana, 225.
} 
psíquico e defende que o fenômeno doloroso seja o paradigma do próprio narcisismo, uma vez que as experiências dolorosas estariam na origem da imagem do corpo.

Seguindo Freud (1915), a dor imita a pulsão, tendo grande semelhança com configurações pulsionais e experiências-limite entre o psíquico e o somático, entre as superfícies interior e exterior do aparelho, todavia, sem ser eficaz do ponto de vista do domínio das sensações corporais de prazer e de desprazer, embora esta última seja a sua finalidade: "a meta da pseudopulsão [dor], no entanto, é tão somente interromper a alteração do órgão e cessar o desprazer vinculado a essa alteração. Outro tipo de prazer, um prazer direto, não pode ser obtido pela interrupção da dor" ${ }^{37}$.

Até o momento, o presente trabalho retomou as formulações sobre a dor física presentes no texto de 1895, O projeto, e conferiu destaque ao Além do princípio do prazer, por esta obra ter um papel central no retorno da experiência da dor e do trauma no

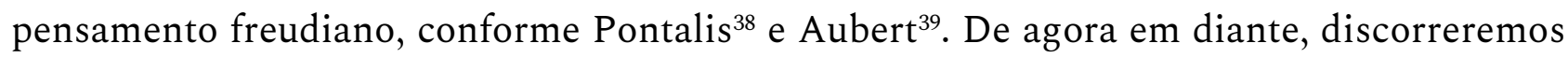
sobre a dimensão da dor como superfície pulsional e processos narcísicos estruturantes das representações do corpo, como descrito nos próximos tópicos, na tentativa de pôr em discussão a economia traumática e formações constitutivas do Eu.

\section{Pseudo-pulsão e a representação corporal}

De forma geral, trata-se de buscar correlações entre os aspectos quantitativos da dor (a captura [Bindung] do excesso de excitação) e o registro qualitativo do problema da dor sua relação com representação do objeto, sua inscrição no psiquismo e o desamparo decorrente da perda do objeto primário. Como vimos, para Freud, a dor física é uma espécie de modelo normal dos processos patológicos, uma vez que ela instala condições anormais no aparelho psíquico, mas sem necessariamente ser patogênica. A partir dos trabalhos da década de 10 e 20 sobre o narcisismo e o mecanismo da identificação, é possível pensar estas condições anormais do aparelho a partir das formações narcísicas e da repetição e transformações do vivido traumático através da elaboração de um corpo pulsional.

Sylvie Le Poulichet, trabalhando com pacientes que apresentam um funcionamento limite, ligado a uma "economia traumática" predominante, em que vivenciam certos processos insólitos de difícil apreensão - como a sensação de estar amorfo ou sem forma (“I'informe), não reconhecer seu rosto ou perder os contornos do corpo (sensação de corpo oco ou cadavérico). Segundo ela, configura-se como um verdadeiro "modo de existir sem

\footnotetext{
${ }^{37}$ FREUD, O relcalque, 177.

${ }^{38}$ PONTALIS, Entre o sonho e a dor, 2005.

${ }^{39}$ AUBERT, A originalidade de uma teoria freudiana, 2017.
} 
existência", em que "esta superfície de deformação toma o lugar da imagem especular por um Eu que não se reconhece" 40 .

A partir do exposto sobre as neuroses traumáticas, a dor ou a lesão concomitante têm condições de oferecer um campo de objetalização possível para a efração traumática, na medida em que aqueles fenômenos constituem uma resposta auto-erótica ou narcísica. Ao fazer isso, mesmo que no modo de defesa narcísica, imprimem uma forma de organização ao eu, uma coesão - às vezes precária - mas que permite traduzir um acontecimento disruptivo e angustiante em um vivido traumático que possa ser contado como experiência social, seja de risco de morte iminente, doença ou uma dor que se adquire: "Tenho dor nos ombros desde então". Uma paciente que sofria com confusões de identidade, processos de despersonalização, entre o que era ela e o que era o outro, seu corpo e o que não é seu, relata "Quando sinto dor, eu me junto. Sinto que estou aqui”. Com efeito, o contra-investimento narcísico a partir de um órgão ou região dolorida promove uma concentração libidinal no eu, semelhante a uma experiência de unificação.

Podemos colocar em questão se tal experiência que produz alterações na tessitura do eu pode também podem substituir limites funcionais como os da camada protetora do paraexcitação e oferecer um contorno real e corporal para sensações difusas ou angústias de morte e aniquilamento do eu. Maria Helena Fernandes aponta que a dor abre um caminho para as representações corporais do eu. Nesse sentido, a dor é parte da constituição do corpo e "essas observações nos convidam a estender essa reflexão à maneira como esse corpo se torna um corpo próprio, possibilitando o acesso à primeira pessoa" ${ }^{41}$. Embora não haja nenhuma garantia de que ter dor é sinônimo de ter um corpo. Refiro-me aqui ao sentido psicanalítico de corpo - unidade corporal, objeto de desejo ou um corpo sexual, do qual a erogeneidade se encontre com processos de simbolização psíquica. No entanto, e ainda assim, a dor é um signo de uma demanda sensível.

A dor pode ser pensada como uma linguagem do corpo, um fenômeno que permite uma apropriação do espaço corporal pelo espaço potencial da palavra. Sendo assim, faz-se um limite, não necessariamente um sintoma, mas uma solução subjetiva que envolve uma lógica de reconhecimento da singularidade ${ }^{42}$. E ainda como aponta Marquez e Peres, a dor física pode estar relacionada à privação do objeto - um objeto investido pelas pulsões sexuais - de modo que sua função é impedir o trabalho de luto e de renúncia à perda, resguardando o sujeito em uma atitude melancólica ${ }^{43}$.

A dor não deve ser pensada apenas como um simples processo de somatização e nem limitada a entidades clínico-diagnósticas, como histeria de conversão, hipocondria, depressões. A dor, antes de tudo, está associada aos modos de expressão do narcisismo

\footnotetext{
${ }^{40}$ LE POULICHET, Psychanalyse de l'informe: dépersonnalisations, addictions, traumatismes, 99.

${ }^{41}$ FERNANDES, Corpo, 116.

42 ZANOTTI; ABELHAUSER; GASPARD; BESSET, Aux limites de l'hystérie, la douler chronique, 432.

${ }^{43}$ MARQUEZ \& PERES, Dor física crônica, melancolia e inibição: articulações freudianas.
} 
estrutural e, portanto, sua investigação teórica e a escuta na clínica do sofrimento psíquico, trazem contribuições para a compreensão da dimensão invisível das configurações do corpo e da imagem narcísica.

Tais figuras põem em ato estados de fragmentação da atividade pulsional, como vimos em Le Poulichet, através da desestabilização da imagem corporal e seu retorno sobre o Eu, em formas impensáveis e ainda não formuladas. No tratamento psicanalítico da dor crônica, por exemplo, após a remissão da queixa dolorosa, costumam emergir fenômenos transitórios de distorção da imagem corporal, como dismorfias e confusões, sensação de anestesia, inadequação sexual ou de identidade. São fenômenos temporários que revelam a relação entre domínios do corpo e a superfície pulsional, em que aquilo que é inconsciente se manifesta sempre como um impróprio (não dominado, não apropriado).

\section{A sombra do objeto e o objeto do masoquismo}

O modelo da dor física nas neuroses traumáticas mostra um modo pelo qual o fenômeno das alterações de órgão e lesões decorrentes têm um efeito regulador na economia traumática e no respectivo sofrimento neurótico, seja pelas intervenções na parte dolorida do corpo - contra-investimento, sobrevalorização - ou em relação à representação do objeto faltante ou ainda sobre o Eu, como veremos. Aqui, o modelo da hipocondria e as identificações narcísicas nos ajudam a entender como uma parte do corpo (um órgão doente) ocupa o lugar de um objeto (da sexualidade ou das pulsões parciais de morte), tornando-o depositário de uma excitação intolerável, no primeiro caso, ou de sensações de cadaverização e desvitalização, no segundo caso.

Nessa situação, uma primitiva angústia de perda está assentada no retorno da sombra do objeto sobre a imagem do corpo, e não sobre o eu, como na melancolia. $\mathrm{Na}$ afecção melancólica, a perda do objeto é substituída pela identificação narcísica com ele: portanto, a melancolia (dor psíquica) se dá pela transformação de um investimento objetal amoroso em identificação narcísica. Propomos que o inverso da fórmula melancólica seja aplicado à explicação de certos estados dolorosos, pela provável substituição de uma identificação narcísica com o objeto por um investimento amoroso (corporal), no qual uma parte do corpo desempenha o papel de objeto narcísico e de representante do objeto externo ausente.

Nesse ponto parece estar a analogia que permitiu a transferência da sensação dolorosa para a esfera mental, pois o intenso investimento de anseio que está concentrado no objeto do qual se sente falta ou que está perdido (um investimento que aumenta com firmeza porque não pode ser apaziguado) cria as mesmas condições econômicas que são criadas pelo investimento da dor na parte danificada do corpo. A transição da dor física para a mental corresponde a uma mudança do investimento narcísico para 
$o$ investimento de objeto. Uma representação de objeto que esteja altamente investida pela necessidade pulsional desempenha o mesmo papel que uma parte do corpo investida por um aumento de estímulo. A natureza contínua do processo de investimento e a impossibilidade de inibi-lo produzem o mesmo estado de desamparo mental ${ }^{44}$.

Esta passagem freudiana, do Adendo C do texto de 1926, descreve a situação em que a criança perde a mãe de vista, que é prototípica para elucidar a passagem da dor física para a dor anímica. Ela remete a definição da dor física e psíquica ao caráter contínuo do sobreinvestimento do representante psíquico, no lugar do corpo dolorido ou do representante do objeto ausente (perdido). Esse sobreinvestimento, quer ele se volte para o corpo ou para a falta do objeto, engendra um estado de desamparo que pode ser sempre retomado e tem um papel significativo na fixação à temporalidade do trauma.

E ainda, esse momento permite abstrair o condicionamento periférico da dor corporal. A ausência do objeto encontra a mesma economia libidinal presente na dor oriunda de uma região ferida, assim a representação de objeto pode ocupar seu lugar. Tal afirmação incide mais de uma vez: "Se a dor não vem de um ponto da pele, mas de um órgão interno, nada muda na situação; apenas sucede que uma porção da periferia interna tomou o lugar da externa" ${ }^{45}$. Seria isso uma reversibilidade entre periferias psíquicas (extremidade perceptiva e o corpo). Também vimos que o choque libera um quantum de energia sexual, esse fenômeno explica por que uma dor externa equivale a uma excitação interna - pseudo pulsão.

Qual registro psíquico predomina no investimento objetal acima descrito: da pulsão, do desejo ou da necessidade? Não seria a passagem do registro da necessidade para o registro da pulsão ou ainda o registro da pulsão para o domínio do desejo. O anseio não pode ser apaziguado quando do reflorescimento do estado de desejo (repetição da vivência de satisfação) e Freud menciona a falta do objeto. Mas como, no início da vida psíquica, um mesmo objeto satisfaz várias pulsões ao mesmo tempo - e ainda são objetos parciais -, não seria esse objeto que se ausenta, antes de tudo, um objeto da necessidade? O anseio de ser amado e o objeto de amor surgem mais tarde. Ao início, a ausência da mãe não é ainda sentida como perda do objeto de amor, mas apenas como uma situação de perigo à sobrevivência da criança, que reage a essa perda primeiro com dor corporal, e não angústia.

É interessante como uma dor aguda, vinculada a um acontecimento corporal traumático pode transitar de um sinal de alerta - situação de perigo - para um processo de cronificação em que "ter a dor" ocupa o lugar das representações do objeto e até mesmo do próprio eu. A queixa ou descrição de estados dolorosos faz frente ao sentimento de vazio

\footnotetext{
${ }^{44}$ FREUD, Inibição, sintoma e angústia, 160. Grifos nossos.

${ }^{45}$ FREUD, Inibição, sintoma e angústia, 121-122
} 
ou desterro: "Melhor isso do que nada" ou na forma masoquista em que "a dor e sua manutenção são visadas como forma de existência, de sensibilidade possíveis: "prefiro sofrer a ter essa vida" ${ }^{4}$.

A propósito, o desprazer da dor não é primário, ele está associado à meta masoquista passiva e às tendências masoquistas do eu, desenvolvidas em $O$ problema econômico do masoquismo (1924). Freud emprega um tom de ressalva quanto ao desprazer específico da dor em Além do princípio do prazer, e também explicita algo interessante em Pulsões e destinos de pulsão (1915): a dor como fruição de prazer sexual concomitante, em nome do qual a dor pode ser tolerada, "as sensações de dor, bem como as outras sensações de desprazer, transbordam para a excitação sexual, produzem um estado prazeroso" ${ }^{47}$.

O sofrimento produzido em estados dolorosos satisfaz exigências sádicas do supereu, como a necessidade de punição e o sentimento de culpa inconsciente ou se presta a torturar familiares, obter ganhos relacionais secundários à doença e um estatuto de demanda externa de reconhecimento. Em O Eu e o Id (1923), Freud discute os ganhos inconscientes da reação terapêutica negativa no caso de neuróticos graves: "está em jogo é um fator 'moral', isto é, um sentimento de culpa que só se apazigua [Befriedigung] no estar doente e que não quer, de modo algum, renunciar ao castigo do sofrimento ${ }^{48}$.

Quando Freud reformula a teoria do masoquismo a partir dos avanços metapsicológicos do segundo dualismo pulsional, recompondo o sadismo como uma expressão da pulsão de morte dirigida para fora (como pulsão de domínio ou destrutividade), enquanto o "masoquismo original e erógeno" é a parcela da pulsão de morte que permanece dentro do organismo, ligada às pulsões de vida, com o auxílio das pulsões sexuais, que "entre a dor e o prazer, teria sido fixada [gebunden] libidinalmente" ${ }^{49}$. A partir de então, a reação terapêutica negativa também será pensada pela via do masoquismo moral, a terceira forma de masoquismo.

Com efeito, indicamos que o conceito de masoquismo primário e as relações entre Supereu, Ideal do Eu e consciência moral [Gewissen] oferecem uma via explicativa alternativa para pensar a produção de fenômenos dolorosos e a compulsão à repetição, indo além série lesão, trauma e defesa narcísica, como discutido nas seções anteriores no caso das neuroses traumáticas e eventos traumáticos. Tendo em vista, alguns indicativos e resultados do presente artigo, parece importante considerar economia traumática sob uma acepção estrutural e desenvolver mais especificamente o papel da dor e do traumatismo na própria neurose e de formas reincidentes de sofrimento e de adoecimento físico, como na dor crônica e outros sintomas psicossomáticos graves. Freud coloca o masoquismo moral como uma forma patológica e extrema de resistência ao trabalho clínico psicanalítico e

\footnotetext{
46 GREEN, Narcisismo de vida, narcisismo de morte, 41.

${ }^{47}$ FREUD, Pulsões e destinos de pulsão, 153.

${ }^{48}$ FREUD, $O$ Eu e o Id, 57-58.

${ }^{49}$ FREUD, O problema econômico do masoquismo, 109.
} 
surpreendentemente uma neurose pode desaparecer "assim que o paciente entra em um casamento infeliz, perde seu matrimônio ou contrai uma perigosa doença orgânica”. Freud coloca que nesses casos uma forma de sofrimento é simplesmente substituída pela outra, “apenas uma questão de manter ativa certa magnitude de sofrimento" ${ }^{50}$.

\section{Considerações finais}

Essa ampliação, contudo, fica como sugestão para trabalhos futuros no campo da teoria psicanalítica, em que se busque uma vinculação entre escolha da neurose e sofrimentos que incidem sobre o plano corporal, como uma das formas de patologias masoquistas do Eu e como efeito da ação da pulsão de morte e sua não inscrição psíquica pelos processos de simbolização. Nesse caso, vemos como o corpo revela sua natureza pulsional e uma plasticidade transformativa a partir das múltiplas repercussões e entranhamentos entre os domínios somático e psíquico, cujo resultado é o duradouro trabalho de construção das representações do $\mathrm{Eu}$, do objeto e do próprio corpo.

O corpo, por sua vez, ora se coloca como um objeto da sexualidade e do erotismo (pulsões de vida), ora como um objeto narcísico apto a realizar tendências mortíferoregressivas em direção a estados de vazio que, por fim, retornam sobre o Eu e o corpo, como atestado nas despersonalizações e outras formas de dissolução do Eu e da imagem corporal. Freud não desenvolveu o problema do narcisismo face às pulsões de morte, como já apontado por André Green na teorização sobre o trabalho do negativo ${ }^{51}$. No entanto, alguns textos de Freud, publicados no início dos anos 20, permitem extrair repercussões do novo dualismo pulsional para o tema do narcisismo e fenômenos ligados às pulsões sexuais e pulsões de morte, como esperamos ter demonstrado em algumas indicações textuais.

Não pode deixar de ser mencionado que "o Eu é sobretudo um Eu corporal, mas ele não é somente um ente de superfície: é, também, ele mesmo, a projeção de uma superfície" ${ }^{52}$. Freud ${ }^{53}$ diz que o corpo, quando tocado, produz percepções distintas sobre o dentro e o fora do domínio corporal. E quando olhado, o corpo (e a imagem que o envolve) torna-se um objeto para o Eu e para as diversas pulsões parciais (escopofílica, sádica, masoquista). O corpo atua à maneira de um dispositivo polimórfico: projeta-se como um outro objeto, contrai traços do objeto externo e se oferece, ele mesmo, como objeto de amor ao $I d$, forma compensatória às perdas narcísicas e pulsionais. Sendo assim, o corpo e

\footnotetext{
${ }^{50}$ FREUD, O problema econômico do masoquismo, 111.

${ }^{51}$ GREEN, Narcisismo de vida, narcisismo de morte, 41.

${ }^{52}$ FREUD, O Eu e o Id, 38.

${ }^{53}$ FREUD, $O$ Eu e $o$ Id.
} 
sua superfície sensível projetam, fundamentalmente, a própria pulsionalidade do aparelho, revelando seu duplo destino, como sujeito e objeto.

Nesse sentido, concluímos com dois apontamentos principais: a) O fenômeno dor e sua relação com o masoquismo originário elucidam o retorno de formações narcísicas sobre o Eu, alterando-o de forma compensatória/regulatória ou adoecedora. b) A investigação sobre o problema econômico da dor e sua regulação narcísica no trauma desvelam, na verdade, a necessidade teórica de maiores elucidações sobre a noção de corpo pulsional e sua relação com o ingresso do outro no psiquismo. Parece que a questão da alteridade e a ausência/presença do outro estão como pano de fundo na situação traumática e talvez já estivessem na origem da própria vivência de dor, por trás das experiências que levaram ao rompimento do escudo protetor do para excitação do ingresso de quantidades maciças de excitação no aparelho psíquico ainda em construção.

Além dos estados afetivos, os intervalos de ausência/presença do objeto parecem ser uma das marcas da vivência de dor, a constituir-se como um legado que sobrevive às duas vivências psíquicas fundamentais (vivência de satisfação e vivência de dor). A dor está presente na vivência de satisfação, como tensão pulsional (o desprazer da fome, atestado pelo grito). Segundo, a dor está na experiência de ruptura e falha dos mecanismos de proteção que a criança pequena e dependente dispõe.

Lembremos que na vivência de dor e na vivência de satisfação temos o mesmo objeto; aquele que é apreendido em sua totalidade só mais tardiamente, qual seja, o agente externo que presta atenção no choro da criança e que realiza a ação específica com a oferta do alimento e outros cuidados, esse também é o objeto hostil. Enfim, aquele que exerce as funções do paraexcitação também atende exigências pulsionais próprias e já esteve sujeito ao mesmo princípio ético de empatia, que é intermitente e jamais uma conquista definitiva. Assim, responde-se apenas periodicamente, por indisponibilidade afetiva ou privações temporárias. Necessariamente o outro e as condições da realidade instauram a falta na mediação entre o sujeito e mundo que o envolve, caracterizando o desamparo performático infantil que um dia fundará a moral do adulto ${ }^{54}$.

\section{Referências}

AUBERT, A. A originalidade de uma teoria freudiana. Trad. Carmen Lucia M. V. Oliveira. São Paulo: Editora Escuta, 2017.

BASTOS, L. A. M. Eu-corpando: o ego e o corpo em Freud. São Paulo: Editora Escuta, 1998.

\footnotetext{
${ }^{54}$ FREUD, O projeto, 363.
} 
BOCCHI, J.C.; CAMPOS, E.B. As somatizações e o problema da dor no pensamento psicossomático clássico. In Porchat, P.; Mouammar, C.C E. (Orgs.). Psicanálise e interfaces. Curitiba: Editora CRV. São Paulo: Cultura Acadêmica Editora, 2018, (Coleção REVER - Psicanálise Unesp n. 4)

BOCCHI, J.C; PEREZ, D.O.; BOCCA, F.V. Ontologie sans miroirs - Essai sur la réalité Borges. Descartes. Locke. Berkeley. Kant. Freud. Traduit du portugais (Brésil) par Isabelle Alcaraz. Paris: L’Harmattan, 2019.

FERNANDES, M. H. Corpo. São Paulo: Casa do Psicólogo, 2011.

FREUD, S. (1905). Três ensaios sobre a teoria da sexualidade. Rio de Janeiro: Imago, 1997.

FREUD, S. (1914). À Guisa de Introdução ao Narcisismo. In Escritos sobre a psicologia do inconsciente (1911-1915) (Vol. I, pp.95-131). Trad. Luiz Alberto Hanns. Rio de Janeiro: Imago, 2004. (Obras psicológicas de Sigmund Freud).

FREUD, S. (1915). O recalque. In Escritos sobre a psicologia do inconsciente (1911-1915) (Vol. I, pp.175-193). Trad. Luiz Alberto Hanns. Rio de Janeiro: Imago, 2004. (Obras psicológicas de Sigmund Freud).

FREUD, S. (1915). Pulsões e destinos da pulsão. In Escritos sobre a psicologia do inconsciente (1911-1915) (Vol. I, pp.133-174). Trad. Luiz Alberto Hanns. Rio de Janeiro: Imago, 2004. (Obras psicológicas de Sigmund Freud).

FREUD, S. (1920). Além do princípio do prazer. In Escritos sobre a psicologia do inconsciente (1911-1915) (Vol. II, pp.123-198). Trad. Luiz Alberto Hanns. Rio de Janeiro: Imago, 2006. (Obras psicológicas de Sigmund Freud).

FREUD, S. (1924). O problema econômico do masoquismo. In Escritos sobre a psicologia do inconsciente (1923-1938) (Vol. III, pp.103-124). Trad. Luiz Alberto Hanns. Rio de Janeiro: Imago, 2007. (Obras psicológicas de Sigmund Freud).

FREUD, S. (1926). Inibição, sintoma e angústia, o futuro de uma ilusão e outros textos (1926-1929). Trad. Paulo César de Souza. Companhia das Letras, São Paulo, 2014.

GABBI Jr., O. F. Notas a Projeto de uma psicologia: as origens utilitaristas da psicanálise. Rio de Janeiro: Imago, 2003.

GREEN, A. Narcisismo de vida, narcisismo de morte. Trad. Claudia Berliner. - São Paulo: Editora Escuta, 1988.

KUPERMANN, D. Estilos do cuidado: a psicanálise e o traumático. 1‥ edição. São Paulo: Zagodoni, 2017.

LE POUliCHET, S. Psychanalyse de l'informe: dépersonnalisations, addictions, traumatismes. Paris: Flammarion Champs Essais, 2009. 
MARQUEZ, I. B.; PERES, R. S. Dor física crônica, melancolia e inibição: articulações freudianas. In: PERES, R. S. Dimensões subjetivas da dor física crônica: perspectivas psicanalíticas. São Carlos: Pedro \& João Editores, 2019.

MARTY, P. A Psicossomática do Adulto. Porto Alegre: Artes Médicas, 1993.

MCDOUGALL, J. Teatros do corpo: o psicossoma em psicanálise. São Paulo: Martins Fontes 2000.

NASIO, J-D. A dor física: uma teoria psicanalítica da dor corporal. Trad. Andre Telles e Lucy Magalhães. Rio de Janeiro: Zahar, 2008.

PONTALIS, J-B. Entre o sonho e a dor. São Paulo: Ideias \& Letras, 2005. (Coleção Psicanálise Século I)

ZANOTTI, S. V. et al. Aux limites de l'hystérie, la douleur chronique. Revista Latinoamericana de Psicopatolia Fundamental, São Paulo , v. 16, n. 3, p. 425-437, Sept.2013. Disponível em: https://www.scielo.br/scielo.php?script=sci_serial\&pid=14154714\&lng=en\&nrm=iso. Acesso em 30. jun.2020. 